\title{
Ideology, Policy, and Practice: Structural Barriers to Collections Diversity in Research and College Libraries
}

\author{
Lori M. Jahnke, Kyle Tanaka, and Christopher A. Palazzolo*
}

Beginning with a discussion of how collections diversity has been conceptualized and assessed within the literature, we then analyze four areas in which professional practices and modes of thinking create barriers to collecting materials from historically marginalized voices. Specifically, we discuss how metadata practices can obscure these materials from acquisitions workflows and user discovery, how relying on use statistics can reinforce existing inequalities. Finally, we discuss how understaffing in key areas and budgetary constraints impede libraries from recognizing and addressing the full scope of the problem.

\section{Introduction}

Much of the recent LIS literature implies that collections diversity is a state that can be achieved, acquired, or accomplished through the delineation of tasks that can be checked off a list. While such recommendations may provide a starting point, they imply that diversity relates to a static state of affairs rather than the ever-changing social and political climate within which library collections exist. It may tempt librarians into thinking of a diverse collection as an achievable goal that can be pursued through a special project or two. On the contrary, we argue that diversity as it relates to library collections is an ongoing pursuit that requires critical engagement with developing areas of scholarship, emerging social justice issues, and critique and re-evaluation of methods. To curate diversity in a collection also requires actively seeking underrepresented peoples and voices. We further argue that several aspects of library management, staffing, the publishing market, and higher education more broadly create structural barriers to developing representative collections.

It is the constraining systemic social and institutional features that inevitably tip the scales toward the mainstream that are the subject of the article. In their discussion of Indigenous archives, Kimberly Christen and Jane Anderson remind us to:

\footnotetext{
${ }^{*}$ Lori M. Jahnke is the Social Sciences Librarian for Anthropology at the Robert W. Woodruff Library, Emory University; e-mail: ljahnke@emory.edu. Kyle Tanaka is a PhD candidate in Philosophy at Emory University; email: kyle.takeshi.tanaka@emory.edu. Christopher A. Palazzolo is the Head of Collection Management and Social Sciences Librarian for Political Science and Economics at the Robert W. Woodruff Library, Emory University; e-mail: cpalazz@emory.edu. (2022 Lori M. Jahnke, Kyle Tanaka, and Christopher A. Palazzolo, AttributionNonCommercial (https://creativecommons.org/licenses/by-nc/4.0/) CC BY-NC.
} 
expose where current cultural authority is placed, valued, and organized within archival workflows. The long arc of collecting is not just rooted in colonial paradigms; it relies on and continually remakes those structures of injustice not only through the seemingly benign practices and processes of the profession, but also through how terms like access and circulation are understood and expressed. ${ }^{1}$

These sentiments are equally relevant to all library collections. However, the organizational complexity of contemporary academic libraries and their relationships with content and service vendors can distract us from the broader structural forces that preemptively restrict the ability of any one individual to address representational equity in library collections.

Although the current term of choice is collections diversity, concerns with how to represent diverse voices have deep roots in the practice of collection management, and, in some cases, there are codified methods intended to promote the collection of opposing views on controversial ideas. ${ }^{2}$ The themes in the LIS literature show a general evolution from the idea of collection diversity supporting intellectual freedom and anticensorship to more contemporary discussions that tend to focus on the characteristics of authors included in collections. ${ }^{3}$ Changing social and political climates during the last four decades have likely contributed to this shift, as well as the recognition that factors beyond materials acquisition (such as who is considered a legitimate knowledge producer and trends in higher education and the publishing market ${ }^{4}$ ) both contribute to and constrain collection development.

We outline four broad structural barriers that librarians face in pursuing equitable representation in their collections: 1) inadequacies of resource description and classification; 2) an over-reliance on use statistics; 3 ) insufficient staffing and available expertise; and 4) budget allocations for materials and operations. We also discuss how an overemphasis on efficiency and scale is inherently opposed to valuing collection diversity. By its very nature, diversity in a system is inefficient and is therefore more costly. To value diversity within any system represents a tradeoff with the cost savings facilitated by uniformity, efficiency, and scale. To put this idea in other terms, developing library collections that exemplify the value of diversity requires an additional investment of resources to overcome structural barriers resulting from broader social inequities, market forces, and professional practices that remake or amplify injustices.

\section{Understanding and Measuring Collections Diversity}

The literature specifically addressing collection management and how diversity is defined is relatively sparse. In 2010, Matthew Ciszek and Courtney Young noted that very little had been written about large-scale diversity collection assessment, ${ }^{5}$ and seven years later Jenny Semenza and colleagues came to a similar conclusion. In their review, only a handful of publications covered the practical issues of collections diversity, such as descriptive metadata and collection assessment, while the majority of publications focused on workforce diversity. ${ }^{6}$ As of July 2020, there were few additions to this body of literature, with the majority of publications focusing on particular topics of diversity, such as race and ethnicity, ${ }^{7}$ LGBTQ representation, ${ }^{8}$ Indigenous knowledge and tribal libraries, ${ }^{9}$ or the role of special collections in addressing diversity. ${ }^{10}$

Although a systematic approach to conceptualizing and measuring diversity is necessary for managing library collections, there are few examples beyond a handful of studies in the 
1980s and 1990s that applied statistical measures of diversity to materials selection and collection assessment. ${ }^{11}$ More common and recent methods of assessing diversity have focused on strategies such as peer comparison lists, award lists, and reviews, ${ }^{12}$ subject bibliographies, ${ }^{13}$ checklists from special interest groups ${ }_{1}^{14}$ public opinion surveys, ${ }^{15}$ and diversity rubrics. ${ }^{16}$ Ciszek and Young offer an overview of these methods along with a discussion of some of the underlying issues for implementing them, ${ }^{17}$ some of which we also discuss below.

A major hindrance in assessing the diversity of collections has been the lack of a shared understanding of what it means for a collection to be diverse, and therefore how this dimension should be assessed. In the 2019 Ithaka Library Survey, only about one-third of respondents indicated that their library had "well-developed" criteria for evaluating the diversity of its collection. ${ }^{18}$ This is despite the fact that, 25 years ago, Serebnick and Quinn had already outlined several of the key questions relating to diversity within public library collections, all of which still pertain to academic collections:

Does the public generally have access in libraries to a wide variety of viewpoints on current and historical issues? How easy is it to find opposing materials on controversial topics? How do we measure whether library collections are "sufficiently" diverse? If some libraries have a higher or lower level of diversity than other libraries, what variables influence the differences? Is it easier for libraries to build diverse collections in some subject areas than in other areas? Do publishing patterns, selection methods, or acquisitions procedures affect diversity levels in libraries? What role may special interest groups have in promoting or inhibiting diversity in library collections? Given the complexities inherent in building collections, is it possible to measure diversity objectively? ${ }^{19}$

Their questions highlight the complexity of understanding, measuring, and maintaining diversity in library collections, particularly when we acknowledge that collections are not just an accumulation of materials, but they must also be evaluated in terms of discoverability and access.

To address this lack of shared understanding, libraries should draw on the conceptual and mathematical models from other fields that can meaningfully characterize the distribution of elements within a system. The fields of conservation biology and ecology probably come to mind immediately; however, science and technology, economics, policy, communications, and many others have a stake in measuring diversity and its sensitivity to changing conditions. The primary goal in all these fields is to characterize the factors that either contribute to or hinder diversity so that desired outcomes can be supported. In science and technology policy, "diversity offers a means to promote innovation, hedge ignorance, mitigate lock-in and accommodate pluralism. It offers one important strategy for achieving qualities of precaution, resilience and robustness that are central to sustainability." ${ }^{20}$

Beyond the field of collection assessment, much of the literature on measuring diversity describes a dual-concept framework, which characterizes diversity as the interaction between two dimensions: the number of categories and the allocation of elements to these categories. ${ }^{21}$ The dimension of categories is often called variety. The distribution of elements within the categories may be represented as proportions or probabilities and is sometimes called balance. In this model, a flat distribution indicates maximum diversity within the system since all types 
of elements are equally represented. In his cross-disciplinary framework for diversity, Stirling outlined a third property called disparity that signifies the degree to which the elements are distinguishable. ${ }^{22}$ Taken together, these three properties answer the questions: How many types of things are there? How much of each type do we have? How different are the types from each other?

The two properties of variety and balance are fairly intuitive in how they might be used to characterize collections, although developing categories is far from unproblematic, as we discuss in the following section. The practices of standardization and classification have been essential tools for acquiring, accessing, and organizing the large volumes of information managed by libraries. However, there are always winners and losers when imposing structures that value economy and uniformity over flexibility and variety. Individuals, ideas, or works that align with the mainstream are rewarded, while those that do not may be excluded. ${ }^{23}$ Olson and Schlegl are alluding to the fundamental tension between system diversity and performance. Even when the benefits of diversity are agreed upon, as in science and technology policy or library collections, pursuing diversification may require prioritizing options that are more costly or difficult to measure, increase transaction costs, limit the benefits of standardization, and attenuate economies of scale. ${ }^{24}$

The concept of disparity may present an even greater challenge than variety due to the complexity of the materials that libraries manage. For example, if the LC classification system provides the property of variety, then it becomes straightforward to assess balance. However, within the LC system a single item could reasonably be classified in more than one way but is ultimately only assigned to one category. This problem is what Stirling refers to as the challenge of accommodating different possible understandings of disparity. ${ }^{25}$ Since disparity is defined by what is seen as the salient dimensions of difference, when categorization and variance are complex, as with library materials, there will be multiple perspectives on what constitutes the salient dimensions. In other words, the salient dimensions depend on the question of interest, which are always informed by the social context. We discuss this problem in more detail in the section on resource description and classification. Despite the challenges of applying Stirling's framework, its application may be particularly helpful for understanding diversity in library collections for several reasons: 1) in fields where no specialized diversity measures exist, such as library collections, it offers a path to a more systematic understanding of diversity; 2) it provides a means to explore the tradeoffs inherent in the diversity premium; 3) rather than pursuing a single definitive index that has the appearance of objectivity, a flexible general heuristic provides a basis for making assumptions transparent by modeling and exploring tradeoffs; 4) implementing a crossdisciplinary framework would allow diversity assessment in collections to articulate more directly with fields such as research and science policy and subject area initiatives.

Applying a heuristic, like Stirling's framework, would represent a dramatic shift in collections analysis from the familiar territory of indices, rankings, and lists. Beyond providing a systematic yet flexible approach, it offers a means to articulate collections diversity with other properties that contribute to system value. For example, Stirling discusses how the measurement of ecological diversity can be articulated with other aspects that might constrain diversity, such as the potential need to conserve species of medical value at the cost of pursuing maximum ecological diversity. ${ }^{26}$ Within library collections, attributes such as publisher, procurement strategy and vendor, language, place of origin, characteristics 
of the author, and institutional affiliation may represent constraints on diversity or otherwise be of interest for diversity assessment. Since there are always tradeoffs that constrain system diversity, articulating diversity with these other aspects allows us to model the effects of decisions and assumptions on the components that contribute to system value. In library collections, it may be useful to articulate diversity measures with, for example, strategic collecting areas and curricular needs, budgeting scenarios, acquisition policies, or any number of factors that may represent a constraint on collecting comprehensively and pursuing knowledge at the margins. It is in the context of tradeoffs and constraints that collections diversity must be measured, or libraries will continue to hide biases under a cloak of standardization, scale, and efficiency.

An aspect of academic library collections that we have not elaborated on is the distinction between assessing the material that a library owns versus the material it makes accessible to its users through interlibrary loan and other cooperative borrowing agreements. Even the most well-resourced libraries must set priorities in terms of collection emphasis since it is not possible to acquire everything. Libraries with fewer resources must engage in even greater tradeoffs. Acknowledging the limitations of budgets, space, and in-house expertise, many libraries have actively pursued collaborative collecting arrangements in recent decades. ${ }^{27}$ Given the near ubiquity of these agreements, it will be a rare case that an academic or college library can be assessed in isolation from the rest of this system. Rather, these services should be considered as one more component in the analysis of collections diversity, weighing both their costs and benefits.

If the broader context of a collection and its role within the lending system is not considered, a rush to establish collections diversity standards, criteria, or benchmarks may carry with it a host of unintended consequences, such as the following: 1 ) discouraging collaborative collection development; 2) penalizing libraries that address specialized local community needs, such as tribal colleges; 3 ) further rewarding libraries that have greater resources to acquire materials; and 4) reducing the overall diversity of materials held by academic institutions. On this last point, libraries striving to optimize their score or alignment with the criteria would end up collecting in similar ways, especially if the criteria include specific content recommendations such as bibliographies or lists. While each local collection might be more diverse, the overall effect on the system would be to reduce diversity and promote duplication. This is not to say that duplication is unwarranted, but to illustrate that coordinated assessment criteria can have system level effects that undermine the original goal.

When considering the entire system of academic library collections, it is important to address the relationship between diversity and rarity. Each library striving to collect rare or unique materials will push the entire system toward diversity. However, this does not necessarily mean that individual collections will be diverse. Individual libraries might choose to focus on a few areas to maximize budgetary and staffing resources, which may lead to a more specialized and less diverse local collection. As long as libraries are choosing different areas of focus, which is to be expected if there is a premium on rarity as has traditionally been the case, then the system will be diverse. While long-term collaborative collection development may have the effect of creating less diverse local collections, this circumstance may be tolerable if users are well supported by robust discovery, interlibrary loan, and cooperative borrowing services. 


\section{Resource Description and Classification}

In this section we discuss two points. First, that biases in indexing result in less intelligible and less cohesive fields associated with diversity efforts, such as gender and sexuality studies and African American studies, to name just two. Second, since indexing relies on terms being commonly used before they are institutionalized via metadata, indexes are unavoidably retrospective. As Sumner Spalding, former Assistant Director for Cataloging at the Library of Congress put it, "LC does not establish usage, but follows it." ${ }^{28}$ Accordingly, fields, disciplines, schools of thought, and other scholarly discussions that fall outside traditional categories will inevitably be assigned to existing categories, thereby fracturing such discussions and reducing their findability for interested scholars.

\section{Biases in Indexing}

Whether selection is informed by systems like Library of Congress Classification (LCC), Library of Congress Subject Headings (LCSH), or vendor-provided metadata, the majority of collection development work relies on bibliographic metadata. However, numerous assessments of indexing adequacy for materials associated with diversity have found such metadata lacking. In practice, this means that metadata cannot be relied upon to identify works that could diversify a collection.

In a seminal study in 1973, Doris Hargrett Clack found that existing subject headings related to African American studies failed to identify materials of interest for that discipline. ${ }^{29}$ In 1995, reflecting on changes in indexing during the past 20 years, Clack found that the switch to online catalogs and the ability to perform Boolean searches somewhat improved the findability of these titles but noted that this required careful combinations of terms since subject headings still failed to identify relevance. ${ }^{30}$ While Clack's work focuses on African American studies, research in other areas has identified similar metadata issues. Looking at women's studies, Kristin Gerhard et al. examined 86 women's studies journals vis-à-vis three indexing services: Women's Studies Index, Women Studies Abstracts, and Studies on Women Abstracts. ${ }^{31}$ They found that 53 out of the 86 journals they examined $(\sim 62 \%)$ were not indexed adequately: articles from the journals either lacked metadata or were inconsistently available (for instance, only half of the articles in the journal were indexed). ${ }^{32}$

The absence of relevant metadata impedes selection of materials in disciplines like African American studies or queer studies in two ways. First, inconsistency in focus means such headings do not necessarily accurately identify relevant characteristics of the item. Clack reports, for example, that with a biography of African American comedian Richard Pryor, "John Alfred Williams' If I stop I'll die: the comedy and tragedy of Richard Pryor the subject headings assigned were: 1. PRYOR, RICHARD. 2. COMEDIANS-UNITED STATESBIOGRAPHY, 3. MOTION PICTURE ACTORS AND ACTRESSES-UNITED STATES-BIOGRAPHY." 33 Note that nothing in the headings indicates that the title would be of interest to, say, a librarian attempting to diversify a collection of comedians. ${ }^{34}$ Second, inconsistency in metadata availability is an issue. For Gerhard et al., erratic indexing made it difficult to determine whether search results were truly representative of all relevant materials. Conducting a slightly broader survey, Vega García found a similar trend held true not only for women's studies but for racial and ethnic studies broadly and concluded that "subject-based periodicals and mainstream periodical indexes overall gave poor and erratic coverage to the literature." ${ }^{35}$ She also found that, in the event a researcher sought items on 
the intersection of two of those terms (such as Latina women), one needed to consult and cross-check multiple indexes. ${ }^{36}$

The unreliability of metadata in areas associated with diversity has significant implications for collection development. As Vega García found, there was a "strong tendency" for Association of Research Library (ARL) members to own African American and Latino periodicals if they were indexed in Ulrich's International Periodicals Directory or Katz's Magazines for Libraries compared to titles that are not indexed. ${ }^{37}$ If materials cannot be found because their metadata do not describe the content effectively or they are inadequately indexed, then neither selectors nor users will necessarily be able to identify relevant materials. This has further implications for basing selection and management decisions on use statistics.

There are two objections to the above examples worth considering here. First, the studies cited here are older (1973/1995, 1993, and 2000). One might assume, therefore, that efforts at updating resource description, such as those through the Cataloging Lab and other initiatives, ${ }^{38}$ coupled with more robust discovery tools render such issues obsolete. However, more recent studies continue to identify issues. Writing on LGBTQ studies, Proctor notes: "Academic library collections are not organized in ways that document the intersectionality of the content collected - a lived experience based on multiple identities cannot be easily captured or documented with Library of Congress (LoC) subject headings or call numbers." 39 Second, and more importantly, one might conclude from the above scenarios that, if the metadata were corrected, this would render such information more reliable for selection decisions. However, the solution is not so straightforward. To address this second point requires a closer examination of the social and historical factors that inform the process of classification and metadata creation.

\section{Emerging Fields, Disciplinary Transformations, and Interdisciplinary Scholarship}

Discussing Eve Sedgwick's Epistemology of the Closet, Melissa Adler notes that the work was classified as PS374 .H63, American literature. ${ }^{40}$ This is perhaps unsurprising, as a cataloger in 1990 "could have no idea that Sedgwick would come to be regarded as one of the founders of queer theory." 41 This scenario and others like it gesture toward a fundamental issue in the process of classification and cataloging. For a title to have metadata that indicates its status as part of a particular subject or discipline, that category must already be established (as an authority record, as a genre, or other category); but, as new disciplines begin to form and split off from existing ones, they may have little more than a loose association of similar interests and concerns, much less an identifiable name. Eventually, queer theory would coalesce into an identifiable discipline accompanied by associated subject headings, but until then metadata cannot render the discipline or subject apparent because it is not yet apparent to the practitioners themselves.

Even once a subject becomes more concrete, this is no guarantee it is well represented via its metadata. Echoing a point made by Deborah Rosenfelt, ${ }^{42}$ Proctor notes that the discipline of LGBTQ studies is highly intersectional; rather than simply focusing on one specific topic or even a list of relatively discrete topics, LGBTQ studies frequently examine the uniqueness of specific interactions (intersections) of identities. Reiterating the point made above by Vega García, Proctor notes that, because of the structure of this metadata, finding relevant titles "requires targeted searches to capture intersectionality." ${ }^{43}$ Rosenfelt notes, for example, 
“women's studies does not lend itself to the traditional taxonomic categories established in language literature [...] its scholars have found their analyses the richer for crossing the boundaries between, say, history and literary criticism." 44

Rosenfelt brings up another significant consideration for collection development in the form of disciplinary evolutions and revisions. First, new perspectives may be integrated in a way that is not fundamentally inclusive, a phenomenon she refers to as "a literary tokenism that would allow the most assimilable to rise but would not question the established literary order." 45 With women writers, for example, it is those authors who write in genres most akin to the canonical works who are included; "great writers" are those who write poetry or novels, not autobiographies, essays, diaries, and the like. Comparing Books for College Libraries, 3rd Edition (BCL3, now Resources for College Libraries) against a bibliography of women's works, Delaney-Lehman found that the majority (59.2\%) were not included, noting that "literary forms that women have often chosen for expression-letters, diaries, autobiography - have not been as highly regarded or attractive as, say, poetry or fiction." 46 Inclusion predicated upon adherence to already-established principles only admits those that most closely follow established norms; those that "pass," one might say.

Second, existing disciplines and canons are in no way immutable. What is considered central to a discipline or a canon changes over time. As Rosenfelt puts it, "The canon [...] is not a given, unchangeable corpus of received works, nor are the standard canonical works the only meritorious ones." 47 This is to say that if one is attempting to diversify a collection by adding, for instance, "poetry," one should be cognizant of the fact that what counts as "poetry" may change over time or, for that matter, what counts as "good" poetry may change. Accordingly, award winners, "best of" lists, and similar resources can shift in their coverage, focus, and scope. New voices and traditions change the contours of disciplines, introducing new terms and challenging the meaning of old ones. What once may have sufficed to represent new and different voices may have become mainstream in a decade's time.

Beyond the more egregious examples of misogyny, racism, and other forms of discrimination in LC headings, there are fundamental issues with the creation of metadata that causes classification to inevitably fail in representing the widest spectrum of views and voices. This is not meant as an indictment of the practice or to say indexing and metadata are useless. It is, rather, to emphasize that curating a diverse collection is a difficult task with constantly evolving goals. A significant reason for this difficulty is that diversity is not a state that can be "achieved"; there is no ultimate checklist that, when complete, allows a library to claim their collection is diverse. Rather, the project is and needs to be ongoing. The boundaries of what is included within a discipline are fluid; therefore, reliance upon reified classification schemes and indexing practices will inevitably fail to capture the range of discourses within that discipline. In other words, even as indexing continues to improve in select areas, managing collection diversity does not necessarily become easier. The dynamism of scholarly pursuits coupled with the legacies of disparity upon which library collections are built requires sustained proactive effort to include scholarship made invisible by academic and social inequalities.

\section{Emphasizing the Mainstream and Reinforcing Marginalization through Use Statistics}

In recent years, there has been a great deal of emphasis on collection development methods that emphasize user data as a basis for selection, weeding, and space allocation decisions. 
The presupposition of this approach equates use with relevance, importance, and quality. However, like Myrna Morales et al., ${ }^{48}$ we argue that basing these decisions on the number of uses is fundamentally problematic for creating a diverse and well-balanced collection, and it risks amplifying existing representational inequalities. Our reasoning is simple: The size of the audience for the content is a critical determining factor for when and how often an item is used. In addition to the problems associated with visibility discussed in the previous section, if a topic of interest has a larger potential audience (for instance, it relates to the mainstream, an established field, is general information, or is associated with a large academic program), then the likelihood that a title will be used is higher. Conversely, if the potential audience is small, the content is likely to have lower use.

Without the context of the potential user group, use statistics as simple frequencies, or even dichotomies (in other words, used or not used), tell us little about the value of the material and are easily confounded by a host of factors, such as research activity levels, access policies, disciplinary conventions, the quality of item metadata, and discovery layer algorithms. Although we are writing more broadly about both print and electronic materials, these ideas echo Rory Litwin's caveats from 2011 on the overreliance of use statistics for selecting electronic materials: 1 ) downloads do not equate to importance; 2) different types of users, such as faculty, graduate students, and undergraduates may use content very differently or relatively more intensively; and 3) aggregate e-book use does not always equate with print circulation. ${ }^{49}$ Amy Fry, ${ }^{50}$ Steven Knowlton, ${ }^{51}$ Karen Kohn, ${ }^{52}$ and others discuss this last point in detail.

Furthermore, a logic that equates use with value benefits established fields and scholars while marginalizing emerging fields, creating additional barriers for scholars from historically underrepresented groups. This same logic also undervalues specialized knowledge. Low-use materials in more specialized areas, or for certain disciplines, may be deemed less important and subsequently be weeded, moved off-site, ${ }^{53}$ or, in the case of use-based acquisition methods, not purchased in the first place.

\section{The Case of Use-based Selection and E-books}

More recently, use statistics have been translated directly into selection methodology. These methods are known by a variety of names such as Demand-Driven Acquisition (DDA), PatronDriven Acquisition (PDA), and Evidence-Based Acquisition (EBA) and have largely been adopted in response to budgetary constraints coupled with administrative pressure to repurpose library spaces away from print collections. Through these methods, a library provides access to content prior to purchasing it and then selections are made based on the use data. This makes a greater amount and wider variety of content available to users, in theory making it possible to diversify a collection by enabling users to select titles that might be missed by traditional collection development strategies. However, it is not clear that use-based selection is effective to this end. Morales et al. write, "while it is tempting to assume that patron-driven collection development practices would result in collections that reflect the diversity of the communities served, such an approach ignores the systemic biases that affect access to the resources necessary for a scholar to publish her work and to have the work marketed and recognized as authoritative. ${ }^{\prime 54}$

Pursuing this line of thought, Rachel Blume examined DDA purchases at the University of Utah's Marriot Library. Analyzing data from the past two years, Blume found that acquisition was driven primarily by a mere three users, one having made 176 purchase requests and 
another having made 88 , totaling $\$ 32,000$ in purchases. ${ }^{55}$ These titles were primarily associated with users in the areas of computer science and international studies, respectively. Blume notes that, when employing DDA, "discussions often assume all members use the service equally," an assumption that is not supported by the data. ${ }^{56}$ Blume adds that this places much of the burden on users interested in non-mainstream issues themselves, as they would have to use the DDA program at "an alarmingly higher rate than the majority in order to have an equal say in the books collected by the library," to say nothing of compensating for "the deficiency created by years of collecting from the majority perspective." ${ }^{57}$ A possible avenue for future research would be to investigate how often and to what degree these dynamics play out in other DDA programs. Even minor effects relative to those reported by Blume are cause for serious concern.

As a method of increasing the diversity of a collection, DDA programs are especially problematic when we consider the potential for them to amplify biases already present in the higher education and publishing industries. If a scholar is unable to have their work recognized as "scholarly" (that is to say, in line with existing disciplinary expectations), they may have no choice but to turn to a small publisher that may have limited distribution networks. As Morales et al. have pointed out, use-based selection cannot circumvent the issues introduced by a pool of titles that is not itself diverse. ${ }^{58} \mathrm{~A}$ further challenge to the use of DDA programs as a tool for increasing collection diversity are Blume's findings that not all users take advantage of them to the same degree. In mediated programs, Blume hypothesizes that this may be because relatively privileged students feel more comfortable making a purchase request, while minority students seek resources elsewhere. ${ }^{59}$ This hypothesis is consistent with other findings demonstrating that "students from more affluent families reported being more comfortable connected to administrators and professors," 60 whereas students from less affluent backgrounds felt uncomfortable asking for various kinds of support. ${ }^{61}$

Some authors have also suggested that patron-driven acquisitions could be leveraged in such a way to "redeploy selectors' efforts and attention towards the 'hand curation' required to build diverse, inclusive and equitable collections." ${ }^{62}$ For example, a newer variation on patron-driven acquisitions, EBA, provides access to a wide swath of e-book content from large publishers for a set period of years. At the end of that term, content is either purchased automatically based on use or it may be hand-selected. The idea is that more automated purchasing and the additional use data would allow selectors to reallocate their time to seeking and vetting materials not covered by the commercial structure, such as ephemera and grey literature, or the products of groups excluded from traditional publishing avenues.

This "leveraging" of EBA and other programs assumes that subject librarians have time dedicated to curating these plans beyond assessing simple usage statistics, allowing them to account for the "maturity" of usage in a field, curricular match and long-term need, and quality of the metadata in the title candidate pool. This idea further assumes that librarians will also have the professional development funding needed to support developing expertise in emerging fields, in addition to the collection funds needed to acquire nonmainstream materials. However, collections funding often becomes more restricted due to e-book pricing models, and "automated" purchasing models provide a rationale for assigning additional responsibilities to subject experts, whether it be more subjects or other administrative and service work. The result is more of the collections budget invested in less content that is selected by the publishers and vendors rather than the librarians connected to the local academic community. 


\section{Insufficient Staffing and Relevant Expertise}

Using time- and labor-saving methods such as approval plans, collection development can be at least partially automated. However, such methods come with drawbacks. Considering the hurdles outlined in the previous sections, for example, one cannot rely upon existing classifications (subject headings, LCC, publisher genres, and the like) to effectively identify relevant materials. This is not to say that such methods are entirely ineffective or that they should be discarded wholesale by libraries. It is, rather, to draw attention to the difficulties involved when works from new and emerging disciplines are classified, or when works from existing disciplines thwart familiar classifications. In such cases, metadata cannot be uncritically relied upon, and additional attention is required to identify and remediate gaps in the collection.

Given that metadata for diversity-related materials is disproportionately erratic, lax, and inconsistent, ongoing engagement with contemporary scholarly discourses is necessary for any librarian attempting to include the diversity of voices from that field. Succinctly put, there is no easy way to collect these materials. This point leads to two further implications to be developed in this section. First, that dedicated specialists are necessary to develop these collections. Second, libraries that lack such staffing must rely on labor-saving collection management methods that may reiterate the systemic exclusions discussed above.

If librarians cannot necessarily rely upon existing metadata to identify relevant materials, they must identify materials by other means. This is where specialized knowledge becomes crucial. To be able to recognize the nuances of an emerging discourse, a specialist must be familiar with its language, figures, and texts. Take, for example, disability studies. Although it emerged in the 1980s, no subject heading existed for the field until 2001. ${ }^{63}$ Any librarian attempting to collect such materials would only be able to do so if they knew about the emerging field, which would require more extensive knowledge of the sources of this information. They would need to consult with departmental faculty, read papers, attend conferences, and follow the efforts of involved researchers to collect the emerging discourse. All of this requires time, effort, and institutional support; a subject librarian who has neither the time to do such research nor the financial support to attend such conferences will necessarily remain in the dark.

Further, beyond librarians themselves, if an emerging field like disability studies - drawing from psychology, sociology, political science, philosophy, and more-is not yet formally recognized as belonging to a discipline, then collecting materials for the field may be haphazard. Since budget allocation and collection development typically follow disciplinary boundaries, any field, and especially an emerging one, will not fall neatly within any of those boundaries. Supposing there is one librarian for each field - a generous assumption-each will only see part of the larger picture that is "disability studies." Thus, each librarian may collect relevant materials if they happen to meet the needs of their department, but the field as a whole will be neglected.

It is a significant expense for a library to maintain a team of specialists to do this kind of work. For smaller libraries and libraries with limited financial resources, such work either weighs heavily on the shoulders of too few staff, or labor-saving methods must be found. In the hopes of finding a more expedient method of assessing diversity in the Oregon State University (OSU) collections, Laurel Kristick compiled a list of titles featured by diversity book awards. ${ }^{64}$ She found that 32 percent of the 2,408 titles identified came from independent presses; she noted, further, that the prevalence of independent presses meant these titles were missed by the library's approval plan. ${ }^{65}$ Two points are especially relevant 
from this project. First, as Kristick points out, it was necessary to consult such lists because the understaffing of acquisitions specialists and subject librarians did not allow for more in-depth analyses of disciplinary discourses and trends. ${ }^{66}$ Second, Kristick notes that, even using this timesaving means, the process of compiling title lists and analyzing the data took several months. ${ }^{67}$

In addition to selection labor, there are logistical costs that must be supported when prioritizing diversity in the collection. More specifically, the acquisition of rare materials or items that are distributed outside of mainstream commercial methods often requires significant changes to existing acquisition workflows and procedures, which may themselves be constrained by broader institutional processes (such as university purchasing policies or state legislatures) and dedicated budget lines. Rachel Blume and Allyson Roylance note that their efforts to decolonize the collection through building relationships with local communities and altering established acquisition processes and metadata practices will challenge dominant and traditional values of efficiency, streamlining, and cost savings. ${ }^{68}$

Results from the 2019 Ithaka report bode ill for developing more robust acquisition and description workflows. One survey indicated that metadata and cataloging along with collections management are two areas in which most respondents expected budget reductions. ${ }^{69}$ Lacking adequate funding and staffing, such departments will inevitably have to make tradeoffs, such as devoting less time to assessing the quality of vendor-supplied metadata, troubleshooting problematic terminology, and developing expertise needed for original cataloging. Although the library world will have to wait to see the effects of these changes, it seems probable that this will result in heavier reliance upon existing terms and, concomitantly, less sensitivity for the necessity of new terms.

\section{Budget Allocation for Materials and Operations}

John Buschman notes that budgets are reflections of administrative priorities, assumptions, and values. ${ }^{70}$ As such, they tend to reveal ideologies or blind spots at the highest levels of organizations where budgets are allocated. Changes in the information market combined with years of budget constraints, and the accumulation of new demands have pushed libraries into a series of tradeoffs that limit their agency regarding the content that is included in the collection, as well as the ability of librarians to effect change both within their organizations and in broader market contexts.

For example, despite early warnings about electronic journal bundling, ${ }^{71}$ widespread adoption of this practice has contributed to the overconsumption of collections budgets, ${ }^{72}$ the underestimation of labor costs in technical areas and maintenance, and deferral of content selection to large, commercial vendors. Even at relatively well-resourced institutions, the proportion of the budget upon which librarians can actively select is quite small. Vincent Larivière et al. argue that the current big deal reflects an oligopolistic marketplace for journal content, in which publishers have taken advantage of inelastic demand and a captive audience. ${ }^{73}$ Additionally, e-book selection, funding, acquisition, and management can be complex and expensive. These activities become cost-effective only when libraries can take advantage of economies of scale. However, restrictive policies for e-book use present both a budgetary and long-term collection challenge for libraries. DDA and EBA models can prove to be unstable over time and difficult to manage effectively, with content transferring in and out of the candidate pool and therefore undermining the integrity of the collection. ${ }^{74}$ 
Fry notes that although e-books may have some benefits, significant barriers remain that primarily serve publishers, such as digital rights management. ${ }^{75}$ William Walters also explores these issues in his series of essays on e-books. ${ }^{76}$ These disadvantages for libraries, in addition to cost, may actually counteract efforts at inclusion and diversity, as e-books may not be as widely shareable as their print counterparts and therefore unsuitable for collaborative collection development initiatives. Thus, as Walters laid out, administrators who argue for greater e-book content need to consider the following: 1) use restrictions; 2) challenges of ownership and leasing; and 3) dominant business models that may reduce accessibility and diversity. ${ }^{77}$ This last point is of particular importance due to the well-noted inflation of e-book prices. ${ }^{78}$

Furthermore, the shift from ownership to leasing and outsourcing as a means to control costs continues to have major implications for libraries and their patrons. For example, in many cases, e-book packages are curated outside of the subscribing library and are often not sustainable in terms of price. As Bailey, Scott, and Best warn in their study of differential costs of print and e-books, "the movement to a predominately e-only format for information is increasing the pressures upon academic libraries to provide access to digital resources, while those resources are in a pricing model reminiscent of the serials pricing models that have bedeviled libraries." ${ }^{\prime 79}$ Although Scherlen and McAllister speak more to the general zeitgeist in academic libraries to repurpose space once dedicated to physical collections, their general warning of relying too heavily on a "single vision" for the transformation and defining of library services is also relevant to current collection development methods. ${ }^{80}$ More specifically, dependence on singular methods (DDA, EBA, approval plans) to cultivate rich, diverse collections is bound to lead to its own set of inequalities, particularly in terms of content. Again, the continued emphasis on singular data-driven approaches to streamline processes and reduce transaction costs may be difficult to reconcile with the more time-intensive nature of building diverse collections.

A greater and potentially disproportionate devotion to e-book plans and e-journal packages can crowd out other budget lines such as investment in open access infrastructure and attention to the selection, acquisition, and processing of less traditional and more diverse materials. Furthermore, these materials may only be available in print formats with limited electronic alternatives. This current disproportionate emphasis or preference for e-materials is of particular concern to area studies scholars, as well as those disciplines in which monographs serve as distinct primary sources and part of the historical record.$^{81}$ For example, many materials in the non-Western world are only available in print, with limited electronic alternatives. ${ }^{82}$ The trend of decreased spending on print materials, which is currently accelerating, ${ }^{83}$ may have the unintended effect of limiting linguistic and cultural diversity in scholarly collections and therefore have a major impact on the representation of marginalized groups. ${ }^{84}$

As noted earlier, there has been a long history and tradition of collaborative collection development initiatives (both in print and e-books) among academic institutions. ${ }^{85}$ Current budget austerity due to the pandemic may lead to a re-emphasis of such approaches, particularly in the building of more diverse collections across the broader library system. In other words, these cooperative arrangements (which could include metadata cooperation) may continue to be a means to achieve broader heterogeneity. Such investment could help in resolving the tension between responding to more immediate curricular needs, while curating and stewarding a broader, forward-looking collection that responds to the requirements of new fields of study and historically excluded voices. Collaborative collection development 
may further allow for respective institutions to concentrate on better representing their local populations in their collections, rather than depending on established diversity lists.

Collection budgets, first and foremost, must support current and evolving curricular and research needs of the community; however, collection decisions should also reflect community values and priorities of openness, diversity, and inclusion. ${ }^{86}$ In addition to the collection budget, investments in collections processing and infrastructure (including staff) should also reflect these values. As collections and related budgets are finite, conscious budget decisions affecting operations and materials must be made to support teaching, research, and diversity principles across the institution. The importance of these new, less traditional emphases may be difficult to convey to administrators, particularly during times of budget austerity, but they are necessary to develop an intentional structure for diversifying the collection. ${ }^{87}$

\section{Conclusion}

We began writing this article prior to the COVID-19 pandemic with no awareness that libraries would soon be confronted with a demonstration of how quickly circumstances can converge to amplify the issues we are highlighting. The recent warning from ACRL in their statement on Equity, Diversity, Inclusion, and the Print Collecting Imperative is well received.

[There are] troubling consequences of a sweeping shift in research libraries toward a collecting paradigm of digital primacy as a monolithic and permanent response to the formidable, but temporary, unforeseen challenges of the COVID-19 crisis. Many of the efficiencies being advocated by library administrations rely on consolidation of acquisitions processes and expansion of arrangements with largescale commercial partners. The business models of these vendors are predicated on economies of scale that privilege materials for which there are well established markets within the academy. ${ }^{88}$

Although the pandemic has brought these issues into sharp relief, the ACRL statement describes a long-emerging trend based on an established mode of thinking. For decades prior to the COVID-19 crisis, libraries had been adopting "creative fiscal approaches" to the "commodification" of the information market, which has often meant prioritizing cost savings at the expense of attentive collection development. Returning to the discussion of use statistics, as Michael Hughes notes, "a major stumbling block to interpreting the use of our collections is the importation of business models, which can [...] confuse budgetary with service standards" and place a disproportionate emphasis on certain types of use and return on investment. ${ }^{89}$ These cost-saving strategies (for example, practices such as outsourcing materials description, package deals for electronic content, leasing content rather than purchasing, and DDA-type programs) have largely favored vendor relationships over investing in collective effort among libraries and are part and parcel of a larger dynamic of business logic within higher education that privileges demand and immediate need over long-term support for scholarship and equity.

While there will always be tradeoffs in terms of budgets, prioritizing collections diversity goes beyond the issues mentioned in the ACRL statement and requires a rethinking of library investment to include the additional resources that are needed to develop and maintain diverse collections. We refer not only to under-resourcing in the collections budget, but also in the other areas discussed above, such as labor (like increased time for selection and vetting 
of content, need for original or local description, novel acquisitions workflows), and the development of expertise (such as professional development funding and the time to engage in it meaningfully).

Whether assessing a particular subject area or the collection writ large, understanding the full cost of curating diverse collections is critical to fulfilling the commitments to diversity, equity, and inclusion emphasized in the mission statements of nearly every college and university. We have highlighted some of the ways that certain professional practices and modes of thinking contribute to or reinforce existing inequalities, as well as the significant issues arising from uncritically relying upon incomplete data to set policy and make decisions related to collection development. While inadequate classification and indexing affects the visibility of scholars and their works within collection management workflows and user-facing services, understaffing in critical areas almost ensures that libraries have no means to identify the full scope of the problem, let alone promote change. The dynamic, fluctuating nature of the political, social, and historical context in which disciplines, subjects, and their associated terms arise further complicates the issue. Curating materials that would diversify collections is a more time- and labor-intensive process than selection of mainstream materials; from this perspective, we have argued that overcoming the many points of erasure requires a more proactive style of collection development in which librarians continually seek out materials on and from voices that are excluded by automated approaches.

\section{Acknowledgments}

We would like to thank our friends and colleagues for the many rich and insightful discussions that helped us explore these issues. We are especially grateful to our colleagues Sandra J. Still and Erica Bruchko for providing feedback on this manuscript.

\section{Notes}

1. Kimberly Christen and Jane Anderson, "Toward Slow Archives," Archival Science 19, no. 2 (June 1, 2019): 90, https://doi.org/10.1007/s10502-019-09307-x.

2. Deborah M. LaFond, Mary K. Van Ullen, and Richard D. Irving, "Diversity in Collection Development: Comparing Access Strategies to Alternative Press Periodicals," College E Research Libraries 61, no. 2 (March 1, 2000): 136-44, https://doi.org/10.5860/crl.61.2.136; Alvin M. Schrader, "A Study of Community Censorship Pressures on Canadian Public Libraries," Canadian Library Journal 49, no. 1 (1992): 29-38; Judith Serebnick and Frank Quinn, "Measuring Diversity of Opinion in Public Library Collections," The Library Quarterly 65, no. 1 (1995): $1-38$.

3. E.E. Lawrence, "The Trouble with Diverse Books, Part I: On the Limits of Conceptual Analysis for Political Negotiation in Library \& Information Science," Journal of Documentation 76, no. 6 (January 1, 2020): 1473-91, https://doi.org/10.1108/JD-04-2020-0057.

4. Sara Ahmed, On Being Included: Racism and Diversity in Institutional Life (Durham, NC: Duke University Press, 2012).

5. Matthew P. Ciszek and Courtney L. Young, "Diversity Collection Assessment in Large Academic Libraries," Collection Building 29, no. 4 (2010): 154-61.

6. Jenny Lynne Semenza, Regina Koury, and Sandra Shropshire, “Diversity at Work in Academic Libraries 2010-2015: An Annotated Bibliography," Collection Building 36, no. 3 (2017): 89-95, https://doi.org/10.1108/CB-122016-0038.

7. Roberto G. Trujillo and David C. Weber, "Academic Library Responses to Cultural Diversity: A Position Paper for the 1990s," Journal of Academic Librarianship 17, no. 3 (July 1991): 157-61; Susan A. Vega García and Kristin H. Gerhard, "Inflation of Diversity Journals in an Academic Library Collection: Implications for Data Tracking in Diversity Collection Development and Maintenance" (Third National Conference on Diversity in Academic Libraries, Iowa City, IA, April 1, 2002), https://lib.dr.iastate.edu/refinst_conf/16; Susan A. Vega García, "Racial and Ethnic Diversity in Academic Library Collections: Ownership and Access of African American and 
U.S. Latino Periodical Literature," Journal of Academic Librarianship 26, no. 5 (September 2000): 311-22, https://doi. org/10.1016/S0099-1333(00)00137-3.

8. Julia Proctor, "Representation in the Collection: Assessing Coverage of LGBTQ Content in an Academic Library Collection," Collection Management 45, no. 3 (January 3, 2020): 223-34, https://doi.org/10.1080/01462679.2 019.1708835.

9. Christen and Anderson, "Toward Slow Archives"; Anjali Gulati, "Diversity in Librarianship: The United States Perspective," IFLA Journal 36, no. 4 (December 1, 2010): 288-93, https://doi.org/10.1177/0340035210388244; Sarah R. Kostelecky et al., "Centering Indigenous Knowledge: Three Southwestern Tribal College and University Library Collections," Collection Management 42, no. 3/4 (October 2, 2017): 180-95, https://doi.org/10.1080/01462679. 2017.1327914.

10. Brian Keough, "Documenting Diversity: Developing Special Collections of Underdocumented Groups," Library Collections, Acquisitions, and Technical Services 26, no. 3 (2002): 241-51, https://doi.org/10.1080/14649055.20 02.10765857; Kathryn M. Neal, “Cultivating Diversity: The Donor Connection," Collection Management 27, no. 2 (June 1, 2002): 33-42, https://doi.org/10.1300/J105v27n02_04.

11. Bert R. Boyce and David Martin, "The Brillouin Measure of an Author's Contribution to a Literature in Psychology," Journal of the American Society for Information Science 32, no. 1 (1981): 73-76, https://doi.org/10.1002/ asi.4630320110; Kathleen Garland, "The Brillouin Information Measure Applied to Materials Selection," Collection Management 3, no. 4 (July 20, 1981): 371-80, https://doi.org/10.1300/J105v03n04_10; Serebnick and Quinn, "Measuring Diversity of Opinion in Public Library Collections."

12. Laurel Kristick, "Diversity Literary Awards: A Tool for Assessing an Academic Library's Collection," Collection Management 45, no. 2 (April 2, 2020): 151-61, https://doi.org/10.1080/01462679.2019.1675209; Proctor, "Representation in the Collection."

13. Maureen J. Delaney-Lehman, "BCL3 and Gender Diversity," Collection Management 19, no. 1/2 (September 26, 1994): 121-26, https://doi.org/10.1300/J105v19n01_07; Maureen J. Delaney-Lehman, "Assessing the Library Collection for Diversity," Collection Management 20, no. 3/4 (1996): 29-37.

14. Judith Serebnick, "Using Checklists to Measure Diversity in Library Collections," Catholic Library World 55, no. 8 (1984): 355-56.

15. Serebnick and Quinn, "Measuring Diversity of Opinion in Public Library Collections."

16. Annabelle Mortensen, "Measuring Diversity in the Collection," Library Journal 144, no. 4 (May 2019): 28-30.

17. Ciszek and Young, "Diversity Collection Assessment in Large Academic Libraries."

18. Jennifer Frederick and Christine Wolff-Eisenberg, "Ithaka S+R US Library Survey 2019" (Ithaka S+R, April 2, 2020), 29, https://doi.org/10.18665/sr.312977.

19. Serebnick and Quinn, "Measuring Diversity of Opinion in Public Library Collections," 2-3.

20. Andy Stirling, "A General Framework for Analysing Diversity in Science, Technology and Society," Journal of the Royal Society Interface 4, no. 15 (August 22, 2007): 715, https://doi.org/10.1098/rsif.2007.0213.

21. For a review, see Daniel G. McDonald and John Dimmick, "The Conceptualization and Measurement of Diversity," Communication Research 30, no. 1 (February 1, 2003): 60-79, https://doi.org/10.1177/0093650202239026.

22. Stirling, "A General Framework for Analysing Diversity in Science, Technology and Society," 709.

23. Hope A. Olson and Rose Schlegl, "Standardization, Objectivity, and User Focus: A Meta-Analysis of Subject Access Critiques," Cataloging E Classification Quarterly 32, no. 2 (September 1, 2001): 62, https://doi.org/10.1300/ J104v32n02_06.

24. For a review, see Stirling, "A General Framework for Analysing Diversity in Science, Technology and Society," 708.

25. Stirling, "A General Framework for Analysing Diversity in Science, Technology and Society," 710.

26. Stirling, "A General Framework for Analysing Diversity in Science, Technology and Society,"712.

27. Helen N. Levenson and Amanda Nichols Hess, "Collaborative Collection Development: Current Perspectives Leading to Future Initiatives," Journal of Academic Librarianship 46, no. 5 (September 2020): 1-2, https://doi. org/10.1016/j.acalib.2020.102201.

28. Olson and Schlegl, "Standardization, Objectivity, and User Focus," 75.

29. Doris Hargrett Clack, "Subject Access to African American Studies Resources in Online Catalogs: Issues and Answers," Cataloging \& Classification Quarterly 19, no. 2 (February 14, 1995): 59, https://doi.org/10.1300/ J104v19n02_04.

30. Clack, "Subject Access to African American Studies Resources in Online Catalogs," 54-55.

31. Kristin H. Gerhard, Trudi E. Jacobson, and Susan G. Williamson, "Indexing Adequacy and Interdisciplinary Journals: The Case of Women's Studies," College E Research Libraries 54, no. 2 (1993): 126, https://doi.org/ https://doi.org/10.5860/crl_54_02_125.

32. Gerhard, Jacobson, and Williamson, "Indexing Adequacy and Interdisciplinary Journals," 132. 
33. Clack, "Subject Access to African American Studies Resources in Online Catalogs," 59.

34. Clack, "Subject Access to African American Studies Resources in Online Catalogs," 58-59.

35. Vega García, "Racial and Ethnic Diversity in Academic Library Collections," 313.

36. Vega García, "Racial and Ethnic Diversity in Academic Library Collections," 313.

37. Vega García, "Racial and Ethnic Diversity in Academic Library Collections," 317.

38. Emily Drabinski, "Queering the Catalog: Queer Theory and the Politics of Correction," Library Quarterly: Information, Community, Policy 83, no. 2 (2013): 97-99, https://doi.org/10.1086/669547; Violet Fox, "Field Reports: The Cataloging Lab," Library Journal 143, no. 6 (April 2018): 12; Steven A. Knowlton, "Three Decades Since Prejudices and Antipathies: A Study of Changes in the Library of Congress Subject Headings," Cataloging \& Classification Quarterly 40, no. 2 (August 2005): 123-45, https://doi.org/10.1300/J104v40n02_08.

39. Proctor, "Representation in the Collection," 4.

40. Melissa Adler, Cruising the Library: Perversities in the Organization of Knowledge (New York, NY: Fordham University Press, 2017), https://doi.org/10.2307/j.ctt1xhr79m.

41. Adler, Cruising the Library, ix.

42. Deborah S. Rosenfelt, "The Politics of Bibliography: Women's Studies and the Literary Canon," in Women in Print 1: Opportunities for Women's Studies Research in Language and Literature, eds. Joan E. Hartman and Ellen Messer-Davidow (New York, NY: Modern Language Association, 1982), 11-31.

43. Proctor, "Representation in the Collection," 10-11.

44. Rosenfelt, "The Politics of Bibliography," 26.

45. Rosenfelt, "The Politics of Bibliography," 22.

46. Delaney-Lehman, "BCL3 and Gender Diversity," 123.

47. Rosenfelt, "The Politics of Bibliography," 4.

48. Myrna Morales, Em Claire Knowles, and Chris Bourg, "Diversity, Social Justice, and the Future of Libraries," portal: Libraries and the Academy 14, no. 3 (2014): 446, https://doi.org/10.1353/pla.2014.0017.

49. Rory Litwin, "Some Objections to Our Use of Library Statistics," Litwin Books \& Library Juice Press (February 26, 2011), https://litwinbooks.com/some-objections-to-our-use-of-library-statistics/.

50. Amy Fry, "Factors Affecting the Use of Print and Electronic Books: A Use Study and Discussion," College $\mathcal{E}$ Research Libraries 79, no. 1 (2018): 68-85, https://doi.org/10.5860/crl.79.1.68.

51. Knowlton, "Three Decades Since Prejudices and Antipathies."

52. Karen Kohn, "Using Logistic Regression to Examine Multiple Factors Related to E-Book Use," Library Resources \& Technical Services 62, no. 2 (April 4, 2018): 54, https://doi.org/10.5860/lrts.62n2.54.

53. Alex D. McAllister and Allan Scherlen, "Weeding with Wisdom: Tuning Deselection of Print Monographs in Book-Reliant Disciplines," Collection Management 42, no. 2 (April 3, 2017): 76-91, https://doi.org/10.1080/0146 2679.2017.1299657; Hilary H. Thompson et al., "Borrowing Latin American Materials in the Big Ten Academic Alliance: A Case Study for Consortial Data Analysis," College \& Research Libraries 80, no. 6 (September 4, 2019): 766-86, https://doi.org/10.5860/crl.80.6.766.

54. Morales, Knowles, and Bourg, "Diversity, Social Justice, and the Future of Libraries," 446.

55. Rachel Blume, "Balance in Demand Driven Acquisitions: The Importance of Mindfulness and Moderation When Utilizing Just in Time Collection Development," Collection Management 44, no. 2-4 (March 26, 2019): 111, https://doi.org/10.1080/01462679.2019.1593908.

56. Blume, "Balance in Demand Driven Acquisitions," 113.

57. Blume, "Balance in Demand Driven Acquisitions," 113.

58. Morales, Knowles, and Bourg, "Diversity, Social Justice, and the Future of Libraries," 446.

59. Blume, "Balance in Demand Driven Acquisitions," 113-14.

60. Anthony Abraham Jack, The Privileged Poor: How Elite Colleges Are Failing Disadvantaged Students (Cambridge, MA: Harvard University Press, 2019), 91.

61. Jack, The Privileged Poor, 94.

62. Sofia Leung, Michelle Baildon, and Nicholas Albaugh, "Applying Concepts of Algorithmic Justice to Reference, Instruction, and Collections Work" (Cambridge, MA: MIT Libraries, 2019), 8, https://hdl.handle. net/1721.1/122343.

63. Library of Congress, “Disability Studies” (Library of Congress, 2001), https://id.loc.gov/authorities/subjects/ sh97005575.html.

64. Kristick, "Diversity Literary Awards."

65. Kristick, "Diversity Literary Awards,"157.

66. Kristick, "Diversity Literary Awards,"158.

67. Kristick, "Diversity Literary Awards,"157.

68. Rachel Blume and Allyson Roylance, "Decolonization in Collection Development: Developing an Authen- 
tic Authorship Workflow," Journal of Academic Librarianship 46, no. 5 (September 2020): 5, https://doi.org/10.1016/j. acalib.2020.102175.

69. Frederick and Wolff-Eisenberg, "Ithaka S+R US Library Survey 2019," 25.

70. John Buschman, Dismantling the Public Sphere: Situating and Sustaining Librarianship in the Age of the New Public Philosophy (Westport, CT: Libraries Unlimited, 2003), 75.

71. Kenneth Frazier, “The Librarians' Dilemma: Contemplating the Costs of the 'Big Deal,"' D-Lib Magazine 7, no. 3 (2001): 1-9.

72. ARL Statistics 2017-2018, eds. Shaneka Morris and Gary Roebuck (Washington, DC: Association of Research Libraries, 2019), Graph 4, https://doi.org/10.29242/stats.2017-2018.

73. Vincent Larivière, Stefanie Haustein, and Philippe Mongeon, "The Oligopoly of Academic Publishers in the Digital Era," PLoS ONE 10, no. 6 (June 10, 2015): e0127502, https://doi.org/10.1371/journal.pone.0127502.

74. Michael Levine-Clark, "Imagining the Future Academic Library Collection," Collection Management 44, no. 2/4 (July 3, 2019): 88-89, https://doi.org/10.1080/01462679.2019.1610680.

75. Amy Fry, "Conventional Wisdom or Faulty Logic? The Recent Literature on Monograph Use and E-Book Acquisition," Library Philosophy and Practice (August 29, 2015), https://digitalcommons.unl.edu/libphilprac/1307.

76. William H. Walters, "E-Books in Academic Libraries: Challenges for Acquisition and Collection Management," portal: Libraries and the Academy 13, no. 2 (2013): 187-211, https://doi.org/10.1353/pla.2013.0012; William H. Walters, "E-Books in Academic Libraries: Challenges for Discovery and Access," Serials Review 39, no. 2 (June 1, 2013): 97-104, https://doi.org/10.1080/00987913.2013.10765501; William H. Walters, “E-Books in Academic Libraries: Challenges for Sharing and Use," Journal of Librarianship and Information Science 46, no. 2 (June 1, 2014): 85-95, https://doi.org/10.1177/0961000612470279; William H. Walters, "The Death and Migration of Book Collections in Academic Libraries," portal: Libraries and the Academy 18, no. 3 (2018): 415-22, https://doi.org/10.1353/pla.2018.0025.

77. Walters, "E-Books in Academic Libraries: Challenges for Sharing and Use" (June 1, 2014).

78. Timothy P. Bailey, Amanda L. Scott, and Rickey D. Best, "Cost Differentials between E-Books and Print in Academic Libraries," College \& Research Libraries 76, no. 1 (2015): 6-18, https://doi.org/10.5860/crl.76.1.6.

79. Bailey, Scott, and Best, "Cost Differentials between E-Books and Print in Academic Libraries," 17.

80. Allan Scherlen and Alex D. McAllister, "Voices Versus Visions: A Commentary on Academic Library Collections and New Directions," Collection Management 44, no. 2/4 (July 3, 2019): 389-95, https://doi.org/10.1080 /01462679.2018.1547999.

81. Sara E. Morris and Jenny Presnell, "Collection Development and the Historical Record: Are We Forgetting Monographs as Primary Sources?" Collection Management 44, no. 2/4 (July 3, 2019): 379-88, https://doi.org/10.108 0/01462679.2019.1597798.

82. Middle East Studies Association, "MELA Statement on Collection Development, Access, and Equity in the Time of COVID-19" (June 22, 2020), https://www.mela.us/2020/06/22/mela-statement-on-collection-developmentaccess-and-equity-in-the-time-of-covid-19/; Seminar for the Acquisition for Latin American Library Materials, "SALALM Resolution: Collection Development in the Time of Covid-19," Seminar on the Acquisition of Latin American Library Materials (June 11, 2020), https://salalm.org/salalm-resolution-collection-development-in-thetime-of-covid-19/.

83. Frederick and Wolff-Eisenberg, “Ithaka S+R US Library Survey 2019,” 21.

84. Hispanic American Periodicals Index (HAPI), "Equity and Access in Higher Education and Academic Libraries amid the COVID-19 Pandemic" (Hispanic American Periodicals Index, September 1, 2020), https:// hapicentral.hapi.ucla.edu/assets/equityandaccessCollDev.pdf.

85. Levenson and Nichols Hess, "Collaborative Collection Development," 1-2.

86. Ellen Finnie and Michael A. Arthur, "Being Earnest with Collections-Voting with Our Dollars: Making a New Home for the Collections Budget in the MIT Libraries," Against the Grain 28, no. 4 (September 1, 2016): 90-92, https://doi.org/10.7771/2380-176X.7496.

87. Blume and Roylance, "Decolonization in Collection Development," 6.

88. Association of College and Research Libraries (ACRL), "ACRL Statement on Equity, Diversity, Inclusion, and the Print Collecting Imperative" (Chicago, IL: Association of College and Research Libraries, October 8, 2020), www.ala.org/acrl/sites/ala.org.acrl/files/content/acrlissues/ACRL_Print_Collecting_Statement.pdf.

89. Michael Hughes, "How I Stopped Worrying and Learned to Love the Usage Data," College E Research Libraries 81, no. 7 (2020): 1172, https://doi.org/10.5860/crl.81.7.1168. 